\title{
Dewatering fine solid suspension by using steam pressure filtration
}

\author{
Hai Thanh Pham 1, 2, ${ }^{*}$, Urs Peuker ${ }^{2}$ \\ ${ }^{1}$ Hanoi University of Mining and Geology, Hanoi, Vietnam \\ 2 TU Bergakademie Freiberg, Freiberg, Germany
}

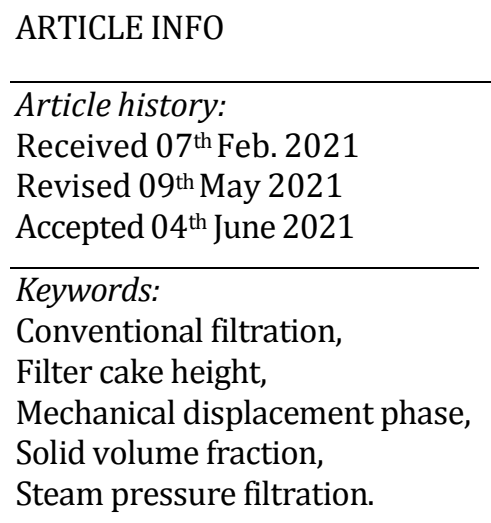

\section{ABSTRACT}

Steam pressure filtration is the combination of mechanical and thermal in one equipment. This process shows the advantages in comparison to conventional pressure filtration by the characteristic of its distinction mechanism. Application of steam pressure filtration can be listed: dewatering the suspension of fine solid, remove the contaminant, dangerous chemical, dissolved ions, protecting the human health as well as the environment. This paper shows the mechanism of steam pressure filtration as well as the result of tests, the comparison related to the efficiency between steam pressure filtration and conventional pressure filtration. The steam pressure filtration shows the high efficiency in mechanical displacement phase in both input parameters: solid volume fraction of suspension and the height of filter cake. The residual moisture content and saturation of filter cake using steam pressure filtration are lower $10 \div 20 \%$ than those values of filter cake using conventional pressure filtration. Moreover, some preliminary tests taking account to the drying phase of steam pressure filtration are also showed. The moisture of fine material filter cakes is around $6 \div 13 \%$. Through the result of tests, interpretation and discussion, the application of steam pressure filtration is possible in the field of mineral processing and metallurgy.

Copyright (C) 2021 Hanoi University of Mining and Geology. All rights reserved.

${ }^{*}$ Corresponding author

E - mail: phamthanhhai@humg.edu.vn

DOI: $10.46326 /$ JMES.2021.62(3b).02 


\title{
Tạp chí Khoa học Kỹ thuật Mỏ - Địa chất
}

Trang điện tử: http://tapchi.humg.edu.vn

\section{Khử nước bùn mịn bằng thiết bị lọc hơi nước cao áp}

\author{
Phạm Thanh Hai 1,2, ${ }^{*}$, Urs Peuker ${ }^{2}$ \\ ${ }^{1}$ Trường Đại học Mỏ - Địa chất, Hà Nội, Việt Nam \\ 2 Đại học Kỹ thuật mỏ Freiberg, Freiberg, CHLB Đức
}

\section{THÔNG TIN BÀI BÁO T TÓM TẮT}

\section{Quá trình:}

Nhận bài 07/02/2021

Sưa xong 09/5/2021

Chấp nhận đăng 04/6/2021

\section{Tù̀ khóa:}

Chiều dày bánh lọc,

Hàm lượng thể tích phần

rắn,

Lọc hơi nước tăng áp,

Lọc truyền thống,

Pha dịch chuyển cơ học.
Lọc hơ nước cao áp là sự kết hợp của quá trình cơ học và nhiệt trong cùng một thiết bị. Quá trình lọc này thể hiên nhiều ưu điểm so với quá trình lọc truyền thống do các đặc điểm khác biệt về bản chất cơ chế. Loc hơ nước được ứng dụng để khử nước bùn min, loại bỏ các tạp chất, hoá chất gây nguy hại đến sức khoẻ con người và môi trường. Đây là vấn đề đang ngày càng được quan tâm từ nhiều nhiều lĩnh vực của ngành công nghiệp, trong đó có lĩnh vực chếbiến khoáng sản, luyện kim. Bài báo giới thiệu về cơ chếcủa công nghệ loc hoi nước cao áp cũng như kết quả thí nghiệm, so sánh hiệu quả lọc khi sử dung loc hoi nước cao áp và loc cao áp truyền thống. Loc hơi nước chứng tỏ được hiệu quả khử nước cao đáng kể trong pha dịch chuyển cơ học ở cả hai thông số đầu vào là hàm lượng thể tích pha rắn của bùn đầu và chiều dày bánh lọc. Độ ẩm và mức độ bã a hoà ở loc hơ nước thấp hơn $10 \div 20 \%$ so với khi sử dụng loc cao áp truyền thống. Ngoài ra, một số kết quả về độ ẩm của sản phẩm khi ứng dụng thêm pha sấy của quá trình lọc cũng được giới thiệu. Độ ẩm cuối cùng với các loại vật liệu siêu mịn dao động $6 \div 13 \%$. Qua các kết quả thí nghiệmcho thấy triển vọng úng dưng phưong pháp lọc mói để khư nước các sản phẩm trong nhà máy tuyển khoáng, luyện kim.

C 2021 Trường Đại học Mỏ - Đia chất. Tất cả các quyền được bảo đảm.

\section{Mở đầu}

Ngày nay, quá trình phân tách pha rắn - lỏng đang dần trở nên phổ biến ở các lĩnh vực của ngành công nghiệp. Quá trình này thường dựa trên hai nguyên lý là lọc và lắng. Trong khi quá trình lắng dựa chủ yếu trên nguyên lý của sự khác nhau về tỷ trọng các pha, quá trình lọc là sự phân tách huyền phù bùn thành hai sản phẩm rắn - lỏng

*Tác giả liên hệ

E- mail: phamthanhhai@humg.edu.vn

DOI: 10.46326/JMES.2021.62(3b).02 thông qua màng lọc (sàng, giấy, vải lọc, màng lọc,...). Các chất rắn được giữ lại trên màng lọc hoặc trong màng lọc (Rushton và nnk., 2015; Svarovsky, 2001). Quá trình lọc được chia làm hai loại chính là lọc với màng lọc dày và lọc bánh. Lọc với màng lọc dày là quá trình loại bỏ hoặc giữ lại các chất rắn không tan bằng cách chặn và giữ lại trong các lớp vật liệu lọc. Lọc bánh là quá trình các hạt chất rắn hình thành lên trên vật liệu lọc, nước lọc trực tiếp đi qua lớp bánh và vải lọc. Quá trình này được ứng dụng phổ biến trong công nghiệp chế biến khoáng sản để khử nước. Trong phạm vi bài báo, quá trình lọc được đề cập là lọc bánh. 
Ứng dụng của quá trình lọc được chia làm hai loại. Thứ nhất là loại bỏ chất rắn hay các thành phần bị nhiễm bẩn khỏi dòng chất lỏng có ích. Ứng dụng này thường gặp trong quá trình xử lý nước sinh hoạt, lọc không khí, lọc các loại nhiên liệu, các yếu tố ô nhiễm môi trường tại các cơ sở chế biến. Ứng dụng thứ hai của lọc là thu hồi các chất rắn có ích, loại bỏ các thành phần dư thừa từ hỗn hợp huyền phù. Ứng dụng này gặp nhiều trong các nhà máy tuyển khoáng, chế biến khoáng sản, các lĩnh vực hoá chất, dược phẩm, luyện kim, tái chế (Sparks, 2016). Có thể nhận thấy, mặc dù có từ lâu đời nhưng lọc vẫn đóng một vai trò không thể thiếu trong các lĩnh vực của cuộc sống và công nghiệp. Vai trò này ngày càng trở nên quan trọng hơn khi chất lượng cuộc sống cần nâng cao, trong khi môi trường (do quá trình công nghiệp hoá) càng trở nên ô nhiễm. Sự cần thiết của quá trình lọc trong các cơ sở công nghiệp, đặc biệt là các nhà máy tuyển khoáng, luyện kim và tái chế càng được chú trọng và đề cao (đặc biệt là vai trò khử nước). Một quá trình lọc tốt dẫn đến các lợi thế: (1) Dễ dàng trong vận chuyển, lưu kho các sản phẩm; (2) Chi phí sản xuất giảm xuống do phần lớn chất lỏng, hoá chất được thu hồi và tái sử sụng (3) Môi trường được cải thiện; (4) Giá trị của sản phẩm sau chế biến được tăng lên, thoả mãn nhu cầu về độ ẩm của khách hàng và các yêu cầu kỹ thuật khác. Tuy nhiên, quá trình lọc đang gặp rất nhiều khó khăn do một trong các yếu tố là độ hạt sản phẩm. Vật liệu vào lọc có độ hạt ngày càng mịn, thậm chí giảm xuống đến vài micromet, thành phần độ hạt rộng (Wakeman, 2007). Công nghệ lọc có những bước thay đổi chậm chạp, chủ yếu dựa vào sự gia tăng áp suất lọc, thay đổi đặc tính của các loại vải lọc. Kết quả sau cùng là độ ẩm sản phẩm vẫn cao, đòi hỏi phải có các công nghệ đắt tiền hơn (công đoạn sấy) và thời gian dài để xử lý (Wiedemann \& Stahl, 1996; Redeker và nnk., 1983). Trong ngành công nghiệp chế biến khoáng sản, không chỉ tinh quặng mà đuôi thải cũng cần phải được khử nước. Giải pháp xây dựng các hồ chứa vẫn đang tranh cãi và nó thực sự tiềm ẩn rất nhiều nguy cơ đến môi trường và hệ sinh thái (Peuker, 2018).

Lọc hơi nước áp suất cao về bản chất là sự kết hợp của hai quá trình nhiệt - cơ học. Quá trình này sử dụng áp suất và nhiệt độ của hơi nước để đẩy nước trong các lỗ rỗng của bánh lọc. Ngoài ra, một lượng lớn nhiệt của hơi nước giúp thúc đẩy quá trình khử nước và làm khô vật liệu. Lọc hơi nước, đặc biệt là lọc hơi nước áp suất cao được ứng dụng trong thực tế từ những năm 90 của thế kỷ trước (Peuker, 2018; Bott \& Langeloh, 1996; Bott và nnk., 2002). Theo như Peuker, mặc dù đã có những nỗ lực trong việc ứng dụng hơi nước, sự kết hợp giữa hơi nước và các thiết bị lọc tăng áp chỉ thực sự giới hạn ở các vùng nhất định của thiết bị lọc. Các kết quả nghiên cứu đồng thời cũng chỉ ra rằng, hơi nước áp suất cao có hiệu quả ở pha thứ hai của quá trình lọc (pha dịch chuyển cơ học) (Gerl, 1999). Hiệu quả của loại lọc này cho thấy ưu điểm vượt trội so với lọc thông thường, đặc biệt với vật liệu mịn và siêu mịn (Peuker, 2018). Đã có các công trình nghiên cứu về hiệu quả khử nước của lọc hơi nước tăng áp trong cải thiện hiệu quả khử nước đối với than (Gerl \& Stahl, 2007; Gerl \& Stahl, 1995; Gerl \& Stahl, 1997; Burton, 1962) thạch anh, quặng sắt (Gerl, 1999), thạch cao (Peuker, 2018; Peuker và nnk., 2001). Theo Peuker, lọc hơi nước cao áp cho kết quả khử nước tuyệt vời với huyền phù bùn mịn, trở lực lọc trung bình và cao. Đối với mục đích khử nước, lọc hơi nước cho thấy hiệu quả ở cả pha thứ hai và pha thứ ba của quá trình (Peuker, 2018). Trong bình luận của Gerl và Stahl, độ ẩm của vật liệu khi sử dụng lọc hơi nước tăng áp cho hiệu quả vượt trội, thậm chí độ ẩm bằng 0 (trạng thái khô hoàn toàn) (Gerl \& Stahl, 2007). Có thể nói thiết bị lọc hơi nước mở ra một xu hướng mới trong khử nước huyền phù, bùn mịn, đặc biệt khử nước, làm sạch hoá chất trong quặng tinh và quặng đuôi, các sản phẩm của tuyển khoáng, luyện kim.

\section{Nguyên lý và thiết bị thí nghiệm}

\subsection{Nguyên lý của quá trình}

Việc sử dụng hơi nước trong các kỹ thuật chế biến là không mới. Hơi nước được ứng dụng rất nhiều trong các lĩnh vực như: sấy, làm nóng, diệt trùng, các quá trình xử lý nhiệt (German Patent No. 498,590, 1930; Burton, 1962; Brown, 1964; Gathen, 1963; Silverblatt \& Dahlstrom, 1964; Peuker \& Stahl, 2001). Hơi nước được ứng dụng trong quá trình lọc theo hai cách. Ở phiên bản giá thành thấp, lọc chân không truyền thống được cải tạo thành lọc chân không hơi nước. Tuy nhiên, phương pháp này không được ứng dụng rộng rãi do không thể tối ưu hoá được các bộ phận cung cấp hơi nước, thoát hơi nước và vòng đệm. Phiên 
bản cao cấp hơn là sự chế tạo thiết bị lọc hơi nước cao áp với thiết bị cấp hơi nước tự động (Peuker và nnk., 2000; 2001; Peuker \& Stahl, 2001a; 2001b).

Lọc hơi nước hoạt động hiệu quả khi hơi nước bão hoà hoặc hơi nước quá nhiệt được cấp vào khi bánh lọc ở trạng thái bão hoà. Hay nói cách khác hơi nước mang lại hiệu quả khử nước cao nhất ở pha dịch chuyển cơ học trong quá trình lọc (Gerl, 1999; Peuker \& Stahl, 2001). Theo Peuker, quá trình lọc hơi nước cao áp cơ bản gồm ba pha: pha hình thành bánh lọc, pha dịch chuyển cơ học (pha khử nước cơ học) và pha sấy.

Pha hình thành bánh lọc về cơ bản tương tự như trong lọc chân không và lọc cao áp truyền thống. Các hạt chất rắn hình thành và nước lọc chảy qua vải lọc. Pha này kết thúc khi bánh lọc đạt trạng thái bão hoà (mức độ bão hoà bằng 1).

Pha dịch chuyển cơ học trong lọc hơi nước cao áp có nguyên lý khác biệt hẳn so với các quá trình lọc truyền thống. Hơi nước áp suất cao được cấp vào bên trên bánh lọc. Do sự chênh lệch áp suất giữa phần bên trên và bên dưới của bánh lọc, hơi nước đi xuyên qua toàn bộ chiều cao của bánh lọc. Hơi nước tiếp xúc với bề mặt lạnh của bánh lọc, ngưng tụ và làm nóng bề mặt đến nhiệt độ sôi. Sau đó, hơi nước đẩy vào trong lỗ rỗng mịn trong bánh lọc. Lớp hơi nước đầu tiên sẽ đẩy nước lọc tồn tại trong các lỗ rỗng của bánh lọc ra ngoài. Một sự ngưng tụ ổn định được diễn ra. Theo đó, hơi nước liên tục được tiêu thụ. Nước ngưng tụ là một lớp nằm giữa hơi nước và lớp nước còn lại trong bánh lọc. Trong quá trình hơi nước đi xuyên qua bánh lọc, một số vị trí cụ thể bị làm nóng đến nhiệt độ sôi. Có thể giả thuyết hệ thống hơi nước và chất lỏng còn lại trong bánh lọc là sự cân bằng nhiệt động học do diện tích bề mặt bên trong của hệ thống xốp cao. Chất lỏng còn lại sẽ thoát ra khỏi bánh lọc và vẫn còn lạnh do sự truyền nhiệt từ lớp nước ngưng tụ vào lượng nước còn lại này chậm hơn rất nhiều so với sự dịch chuyển cơ học. Quá trình này kết thúc khi hơi nước đi xuyên qua bánh lọc. Sự xâm nhập của lớp nước ngưng tụ (còn được gọi là lớp nước dịch chuyển) góp phần giảm hầu hết nước ở trong các lỗ rỗng của bánh lọc một cách đồng thời, không phân biệt kích thước lỗ rỗng lớn hay nhỏ. Điều này thể hiện ưu điểm vượt trội so với lọc truyền thống, khi mà nước thường bị giữ lại trong các lỗ rỗng nhỏ của bánh lọc, làm tăng độ ẩm của vật liệu. Cơ chế hoạt động của lớp dịch chuyển cơ học được mô tả chi tiết trong nghiên cứu của Peuker (Peuker \& Stahl, 2001).

Pha thứ ba của quá trình lọc là pha sấy. Hơi nước bão hoà, hơi nước quá nhiệt hay bất kỳ loại khí nào cũng có thể được sử dụng. Nếu hơi nước bão hoà hay hơi nước quá nhiệt được sử dụng, bánh lọc là một thành phần thống nhất. Năng lượng cho quá trình sấy được cung cấp bởi dòng chảy của hơi nước. Tính thấm của bánh lọc và mức độ quá nhiệt của hơi nước sẽ quyết định đến tỷ số sấy nếu không khí hay khí Nitơ được sử dụng. Sự cân bằng nhiệt động học sẽ xác định sự bốc hơi của lượng nước còn lại trong bánh lọc. Lượng nhiệt trong bánh lọc là nguyên nhân cho sự bốc hơi của lượng nước còn lại. Khi bánh lọc giảm đến nhiệt độ sôi, vai trò của dòng không khí chỉ có ý nghĩa vận chuyển hơi nước bị bốc hơi trong bánh lọc.

Hiệu quả của quá trình lọc hơi nước và lọc truyền thống được mô tả trong Hình 1 . Đường cong màu đỏ mô tả quá trình lọc sử dụng hơi nước. Đường màu xanh còn lại mô tả quá trình lọc sử dụng khí nén. Pha dịch chuyển cơ học đánh dấu sự kết thúc khi dòng khí/hơi nước đi xuyên qua (air/steam breakthrough). Pha dịch chuyển cơ học của hai quá trình có sự khác nhau do hơi nước cần nhiều thời gian để ngưng tụ, truyền nhiệt cho bánh lọc, đẩy nước trong bánh lọc ra ngoài. Có thể thấy pha thứ hai áp dụng hơi nước, pha thứ ba áp dụng khí để sấy cho độ ẩm thấp hơn đáng kể so với quá trình lọc truyền thống và quá trình lọc sử dụng hơi bão hoà trong pha sấy.

\subsection{Thiết bị thí nghiệm}

Thiết bị lọc hơi nước cao áp được chế tạo và lắp đặt dựa trên thiết bị lọc áp suất cao truyền thống Nutsche. Toàn bộ thiết bị gồm một ống trụ thép không gỉ dẫn khí chứa bùn đầu. Tiết diện ống là 19,64 cm². Vải lọc được đỡ bằng thiết bị đỡ vải lọc, có chứa đĩa đục lỗ bằng thép không gỉ và có cùng tiết diện với ống Nutsche. Kết nối giữa ống Nutsche và thiết bị chứa vải lọc là bộ phận chứa bánh lọc. Các bộ phận này có thể dễ dàng tháo lắp, vệ sinh. Ống Nutsche kết nối với van điều áp để điều chỉnh áp suất không khí cấp vào. Phần nắp bên trên của ống Nutsche có kính trong để quan sát bánh lọc bên trong. Bên cạnh đường ống cấp không khí áp suất cao, Nutsche còn có một đường ống cấp hơi nước bão hoà được điều chỉnh bằng 


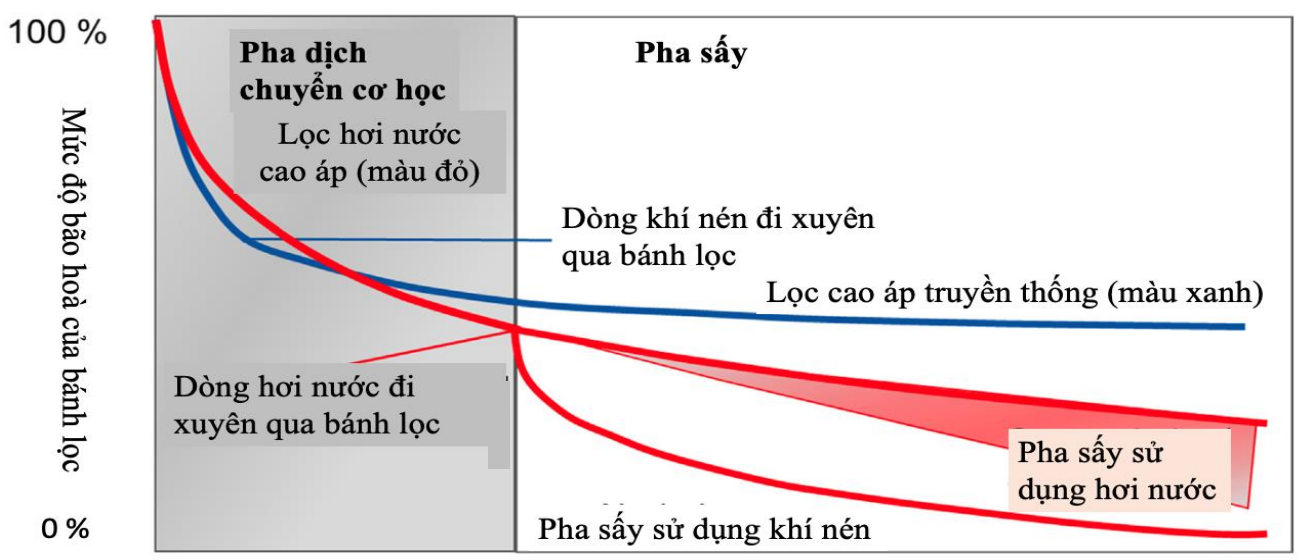

Tỷ lệ thời gian tương ứng hai pha (dịch chuyển cơ học - sấy) của quá trình

Hình 1. So đồ của pha dịch chuyển co học và pha sấy (drying phase) sử dụng lọc hơ nước cao áp và lọc cao áp truyền thống. So đồ được thể hiện dựa trên mối quan hệ của thời gian và múc độ bão hoà trong bánh lọc (Peuker \& Stahl, 2001; Esser \& Peuker, 2020).

van từ đóng mở (magneticvalve) và van điều chỉnh áp suất. Toàn bộ thiết bị và đường ống được làm nóng từ máy cung cấp nhiệt và được bao bọc bởi bông cách nhiệt. Mục đích của việc này là ngăn hơi nước bị ngưng tụ trong quá trình cấp cho Nutsche và sự trao đổi nhiệt với môi trường xung quanh. Hơi nước được cung cấp từ thiết bị cung cấp hơi (evaporator). Dòng hơi này có thể là hơi quá nhiệt nếu nhiệt độ của đường ống dẫn hơi cao hơn nhiệt độ hơi nước tại vị trí đó. Can nhiệt được sử dụng ở vị trí thấp nhất của bánh lọc, tiếp xúc với vải lọc, nhằm mục đích xác định thời điểm hơi nước đi qua bánh lọc. Hình ảnh của thiết bị và sơ đồ cấu tạo hệ thống thí nghiệm được thể hiện ở các Hình 2, 3.

\subsection{Trình tự thí nghiệm}

Huyền phù bùn đầu được tạo ra theo trình tự như sau: chất rắn được khuấy cùng với nước cất ở nhiệt độ phòng $\left(20^{\circ} \mathrm{C}\right)$ trong thời gian 5 phút để đạt được mức độ phân tán đồng đều nhất. Lượng nước để pha huyền phù bùn mịn phụ thuộc vào lượng chất rắn cũng như hàm lượng pha rắn của bùn trong từng thí nghiệm. Sau đó, bùn được cấp vào Nutsche và đóng nắp lại. Như đã thảo luận ở trên, hiệu quả vượt trội của lọc hơi nước diễn ra chủ yếu ở pha thứ hai của quá trình lọc. Do đó, phạm vi nghiên cứu của hầu hết các thí nghiệm đều dừng lại ở pha dịch chuyển cơ học này. Ở pha đầu tiên của quá trình lọc, bánh lọc được hình thành nhờ sự chênh lệch áp suất của khí nén được cấp vào Nutsche. Vải lọc được sử dụng là vải lọc cơ bản cho các thí nghiệm lọc SK006. Đây là loại vải lọc được dệt bằng sợi satin, với kích thước lỗ rỗng $6 \mu \mathrm{m}$, tính thấm khí là $15 \mathrm{~m}^{3} / \mathrm{m}^{2} / \mathrm{h}$. Bánh lọc hình thành trong khi nước lọc chảy xuyên qua vải lọc. Pha đầu tiên kết thúc khi mức độ bão hoà của bánh lọc xấp xỉ 1 . Việc xác định thời điểm này nhờ quan sát được lớp nước mỏng trên bề mặt bánh lọc qua kính của nắp Nutsche. Ngay khi độ bão hoà đạt được, không khí được xả hết ra khỏi Nutsche.

Pha tiếp theo là dịch chuyển cơ học. Tuỳ thuộc vào phương pháp lọc truyền thống hay lọc hơi nước mà khí nén hay hơi bão hoà được sử dụng. Đối với lọc cao áp thông thường, không khí được cấp vào trong Nutsche nhằm đẩy nước trong bánh lọc ra ngoài. Pha này kết thúc khi không khí đi xuyên qua bánh lọc. Đối với lọc hơi nước cao áp, trình tự thí nghiệm có phức tạp hơn. Hơi nước bão hoà được cấp vào Nutsche. Một lưu ý đó là trong khoảng 2 giây đầu tiên sau khi mở van từ cấp hơi nước, van thoát hơi trong Nutsche phải được mở.

Mục đích quá trình là đẩy hết không khí thừa trong pha đầu tiên, làm giảm hiện tượng hình thành những túi khí trong các lỗ rỗng bánh lọc (Peuker \& Stahl, 2001; Esser \& Peuker, 2020). Sau đó, van thoát hơi phải được đóng vào để hơi nước đẩy lượng nước còn lại ra khỏi bánh lọc. Thí nghiệm được tiến hành với hơi nước bão hoà đến khi hơi nước thoát ra khỏi bánh lọc. Hiện tượng này được quan sát tương ứng với nhiệt độ can nhiệt tại vải lọc đạt xấp xỉ $100^{\circ} \mathrm{C}$. 


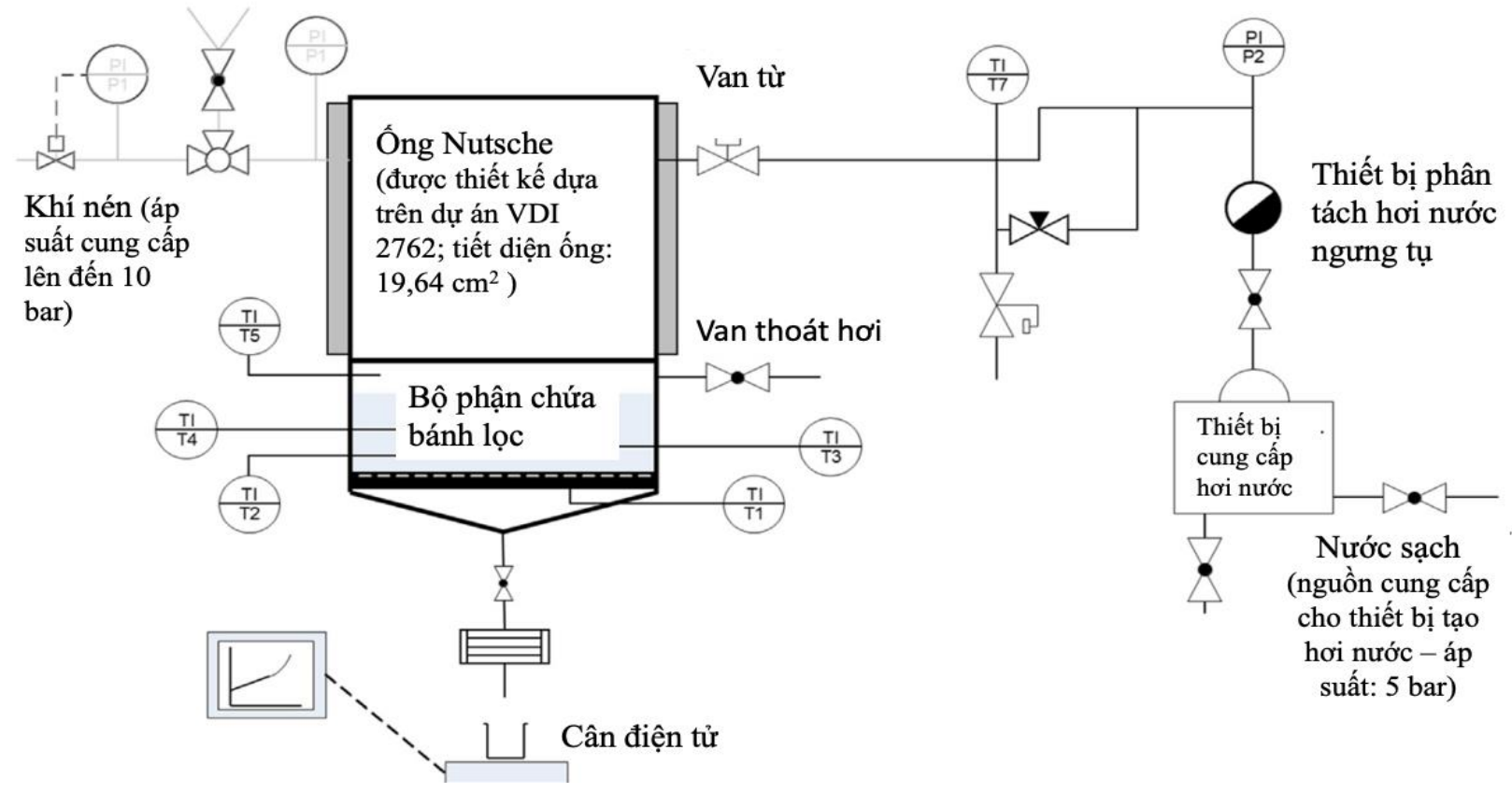

Hình 2. So đồ thiết bị lọc hoi nước cao áp thí nghiệm (Esser \& Peuker, 2020) (Data in Brief)), (VDI - 2762, 2010).
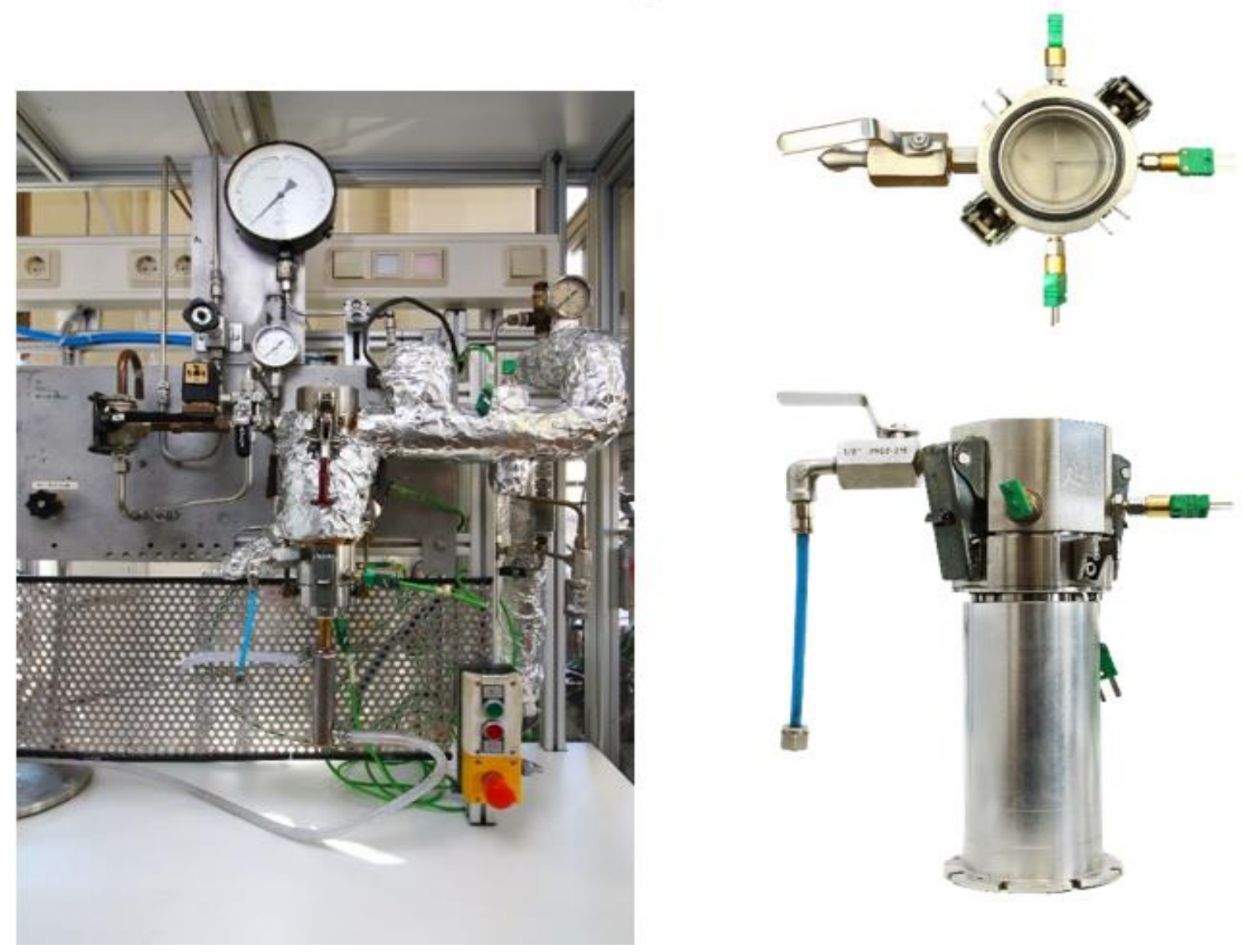

Hình 3. Thiết bị thí nghiệm lọc hơi nước cao áp (Esser \& Peuker, 2020), (Esser \& Peuker, 2020 (Data in Brief)). 
Pha dịch chuyển thứ hai kết thúc. Nutsche sau đó được xả hơi nước còn lại một cách từ từ nhằm ngăn ngừa bánh lọc bị phá huỷ cũng như hiện tượng bốc hơi của lượng nước còn lại trong bánh lọc. Từ đó, sai lệch độ ẩm do sai số hệ thống có thể được loại trù̀.

Bánh lọc được xác định ngay chiều cao, khối lượng trước khi đưa vào tủ sấy. Nhiệt độ sấy là $50^{\circ} \mathrm{C}\left( \pm 5^{\circ} \mathrm{C}\right)$. Việc xác định các thông số của bánh lọc giúp tính toán cụ thể độ ẩm và mức độ bão hoà của bánh lọc. Từ đó có các so sánh, đánh giá kết quả giữa hai phương pháp lọc.

Thông số tương ứng để đánh giá hiệu quả của quá trình lọc là mức độ bão hoà và độ ẩm còn lại. Mức độ bão hoà được xác định theo công thức:

$S=\frac{V_{\text {lượng nước còn lại }}}{V_{\text {lỗ rỗng }}}=\frac{V_{\text {lượng nước còn lại }}}{h \cdot A-m_{S} / \rho_{S}}$

Trong đó: $S$ - mức độ bão hoà; $V_{\text {luợng nước còn lạiv }}$ $V_{\text {lỗ rông }}$ - lần lượt là thể tích của lượng nước còn lại bánh lọc và lố rỗng trong bánh lọc; $h$ - chiều cao của bánh lọc; $A$ - diện tích bánh lọc; $m_{s,} \rho_{s}$ - lần lượt là khối lượng và khối lượng riêng của chất rắn.

Ngoài ra, một thông số rất thông thuộc và phổ biến hơn cả là độ ẩm của bánh lọc:

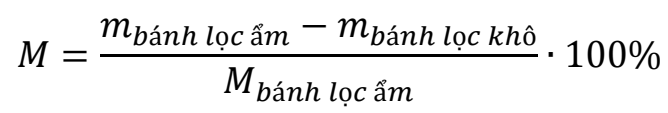

Trong đó: $M$ - độ ẩm của bánh lọc (\%); $m$ khối lượng của bánh lọc ở các trạng thái khác nhau (gam).

\section{Kết quả và thảo luận}

\subsection{Vật liệu nghiên cúru}

Vật liệu được sử dụng là đá vôi KS12 với tỷ trọng là 2,71 , kích thước hạt trung bình là $2,46 \mu \mathrm{m}$. Vật liệu có độ rộng phân phối của thành phần độ hạt $\left(x_{90}-x_{10}\right) / x_{50}$ là 2,98 . Thành phần độ hạt và mật độ phân phối các cấp hạt được trình bày ở số liệu Hình 4, 5. Số liệu về đặc điểm độ hạt được tiến hành bằng phương pháp nhiễu xạ laser và kính hiển vi điện tử quét.

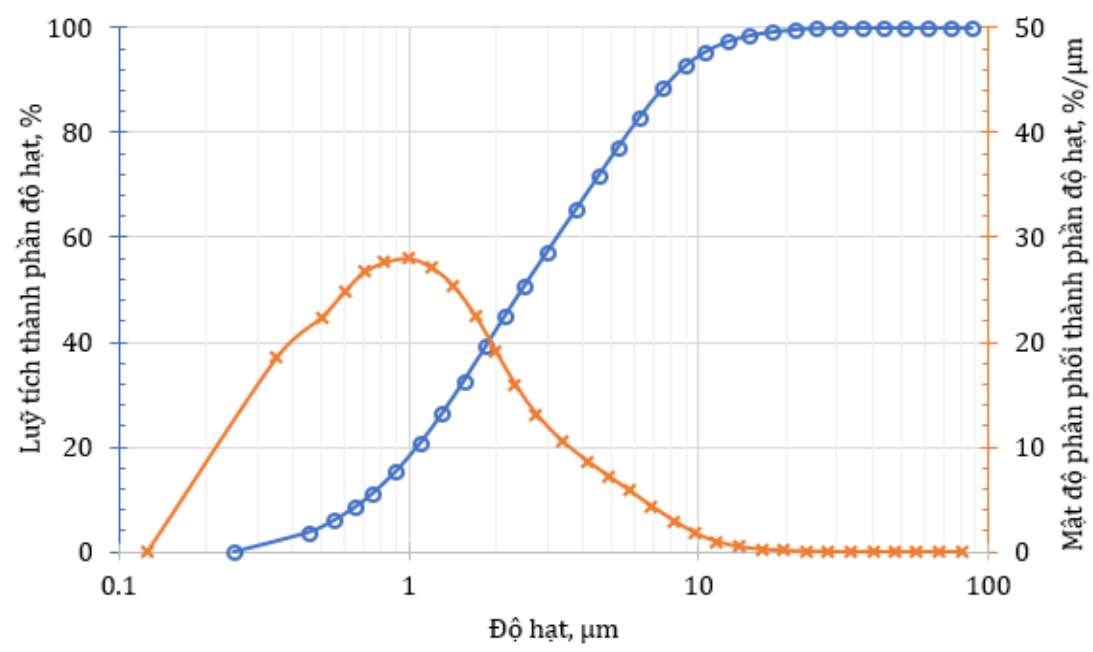

Hình 4. Luỹ tích thành phần độ hạt và mật độ phân phối thành phần độ hạt.
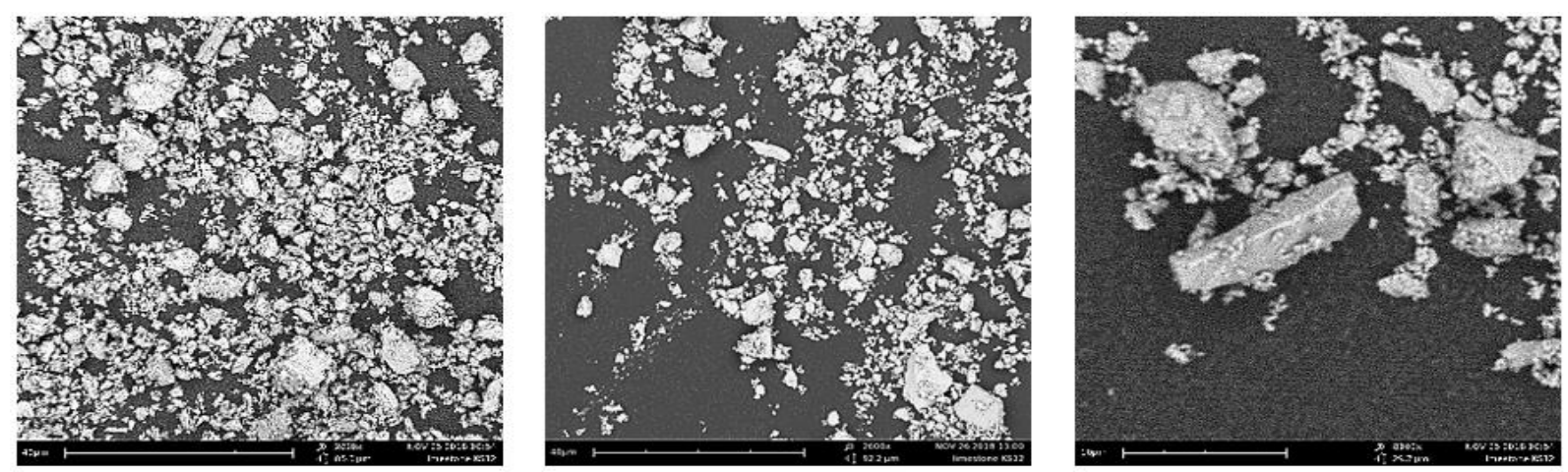

Hình 5. Hình dạng và kích thước các hạt vật liệu đá vôi KS12. 
Có thểnhận thấy tỷ lệ của các hạt mịn nhỏ hơn $10 \mu \mathrm{m}$ của vật liệu là 94,51\%. Tỷ lệ này là rất cao, được dự đoán ảnh hưởng lớn đến hiệu quả khử nước của quá trình lọc. Ngoài ra, kết quả nghiên cứu đặc điểm vật liệu cũng chỉ ra hình dạng khối không đều của vật liệu với rất nhiều các kết hạn siêu mịn. Để đảm bảo vật liệu được phân tán tốt trong quá trình thí nghiệm, huyền phù được khuấy kết hợp với siêu âm.

\subsection{Kết quả thí nghiệm}

3.2.1. Ảnh hưởng của hàm lượng thể tích pha rắn trong bùn đầu

Thông số đầu tiên được nghiên cứu là hàm lượng pha rắn trong bùn đầu. Đây là một trong số những thông số đầu vào quan trọng của quá trình lọc. Thông số này ảnh hưởng đến hiệu quả của quá trình lọc, sự sa lắng của các hạt chất rắn trong máy lọc, cấu trúc bánh lọc và thời gian lọc. Việc nghiên cứu thông số đầu vào này đưa ra một hiểu biết sâu hơn về cơ chế, hành vi khử nước của bánh lọc, lựa chọn được thông số phù hợp cho các nghiên cứu tiếp theo, đồng thời là sự gợi ý tốt cho quy mô lớn hơn (bán công nghiệp và công nghiệp).

Giá trị hàm lượng pha rắn trong bùn đầu được xác định là tỷ lệ thể tích chất rắn trong bùn so với thể tích bùn đầu đưa vào lọc. Các giá trị này tăng từ 0,05 đến 0,35 (tương ứng là $5 \div 35 \%$ ) bởi sự cố định khối lượng chất rắn 50 gram và thay đổi lượng nước. Nước cất được sử dụng trong toàn bộ các thí nghiệm nhằm loại bỏ ảnh hưởng của các

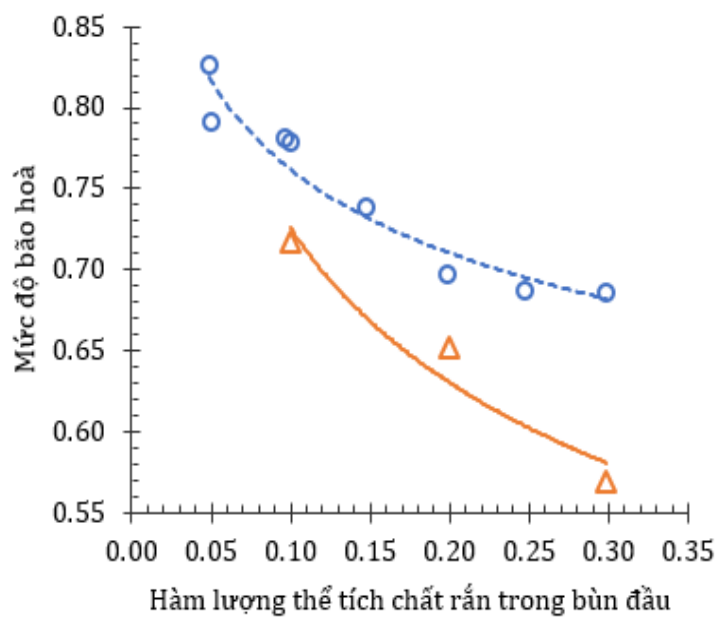

Hình 6. Mức độ bão hoà và độ ẩm của vật liệu thay đổi khi tăng hàm lương thể tích chất rắn trong bùn đầu; chiều cao bánh lọc 18 mm; áp suất 3 - 3 bar. (ký hiệu hình tròn, nét đứt: lọc tăng áp truyền thống; ký hiệu tam giác, nét liền: lọc hơ nước tăng áp). ion đến quá trình lọc. Chiều dày bánh lọc tương ứng với khối lượng đá vôi sử dụng là xấp xỉ $18 \mathrm{~mm}$. Độ chênh áp suất ứng dụng là 3 - 3 bar (3 bar đối với quá trình hình thành bánh lọc, 3 bar đối với quá trình dịch chuyển cơ học). Thí nghiệm được tiến hành trên thiết bị lọc cao áp truyền thống và thiết bị lọc cao áp hơi nước. Kết quả thí nghiệm như ở Hình 6.

Kết quả thí nghiệm cho thấy hiệu quả rõ rệt của lọc hơi nước so với lọc truyền thống. Giá trị độ ẩm tính theo khối lượng nước còn lại và độ bão hoà tính theo thể tích nước còn lại đều thấp hơn khoảng $10 \div 20 \%$. Có thể nhận xét hiệu quả dịch chuyển cơ học của hơi nước tốt so với không khí do có thể đẩy lượng nước dư thừa trong bánh lọc ở những lỗ rỗng to và nhỏ trong bánh lọc.

Một vấn đề nữa được quan sát thấy ở đây đó là xu hướng giảm lượng nước trong bánh lọc khi lọc bùn đặc. Điều này có thể giải thích dựa vào hiện tượng sa lắng của các chất rắn trong quá trình hình thành bánh lọc. Hiện tượng cũng được mô tả rõ ràng trong các nghiên cứu về ảnh hưởng của nồng độ bùn trong hình thành vết nứt trong bánh lọc (Pham \& Peuker, 2020) hay trong nghiên cứu về ảnh hưởng của nồng độ bùn đến cấu trúc bánh lọc (Löwer và nnk., 2020). Ở nồng độ bùn loãng $(0,05$ và 0,1$)$, sự sa lắng diễn ra mạnh mẽ hơn do các hạt rơi tự do. Một lớp các vật liệu hạt mịn hình thành ở lớp trên cùng của bánh lọc. Lớp mịn này cần độ chênh áp cao hơn đáng kể để có thể thực sự được khử nước trong pha dịch chuyển cơ học. Kết quả là nước bị giữ lại nhiều hơn trong bánh lọc

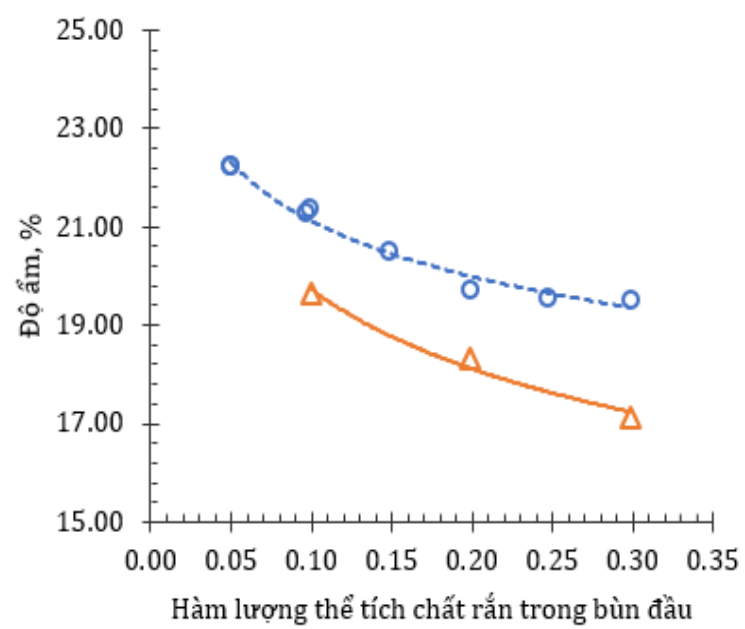


so với khi lọc ở nồng độ bùn cao. Sự sa lắng của các hạt trong quá trình hình thành bánh lọc được minh chứng bằng đường cong của đồ thị "thời gian/thể tích nước lọc" và "thể tích nước lọc" trong Hình 7. Quá trình hình thành bánh lọc diễn ra hoàn hảo nếu đường đồ thị trên là đường thẳng. Đường này sẽ là đường cong khi xuất hiện hiện tượng lắng (VDI - 2762, 2010), (Gösele, Alt, \& Loeve, 2005).

\subsection{2. Ảnh hưởng của chiều dày bánh lọc}

Thông số chiều dày bánh lọc là một thông số quan trọng. Việc lựa chọn đúng đắn thông số này khiến quá trình lọc không chỉ đạt được năng suất cao nhất mà còn mang lại hiệu quả khử nước tốt nhất. Đây còn là một thông số quan trọng trong tăng kích thước của máy lọc lên quy mô bán công nghiệp hay công nghiệp.

Thí nghiệm được tiến hành dựa trên sự cố định hàm lượng thể tích pha rắn 0,1 ; độ chênh áp 3 - 3 bar (3 bar đối với pha hình thành bánh lọc, 3 bar đối với pha dịch chuyển cơ học). Chiều dày bánh lọc được thay đổi dựa vào sự thay đổi khối lượng của đá vôi. Kết quả thí nghiệm được tiến hành trên thiết bị lọc truyền thống và lọc hơi nước, được cho ở Hình 8.

Nhìn chung, độ ẩm và mức độ bão hoà của bánh lọc khi sử dụng lọc hơi nước thấp hơn khoảng $20 \%$ so với kết quả khi sử dụng lọc truyền thống. Kết quả này thể hiện ưu điểm của lọc hơi nước. Cần lưu ý rằng tất cả các thí nghiệm chỉ dừng lại ở pha dịch chuyển cơ học, nơi mà hiệu ứng cơ học quyết định lượng nước tồn tại trong bánh lọc. Xa hơn khi nghiên cứu hiệu ứng nhiệt do lọc hơi

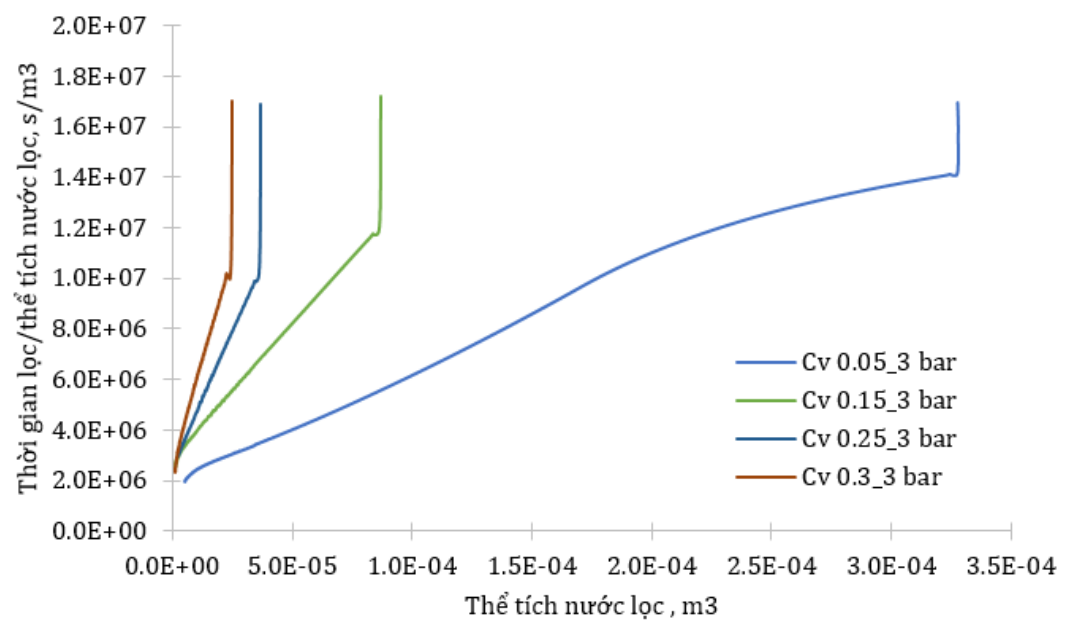

Hình 7. Mối quan hê giữa tỷ lẹ "thời gian lọc/thể tích nước lọc" và "thể tích nước lọc" khi lọc bùn ở áp suất 3 bar, chiều cao bánh lọc 18 mm, nồng độ thể tích chất rắn thay đổi (cv).
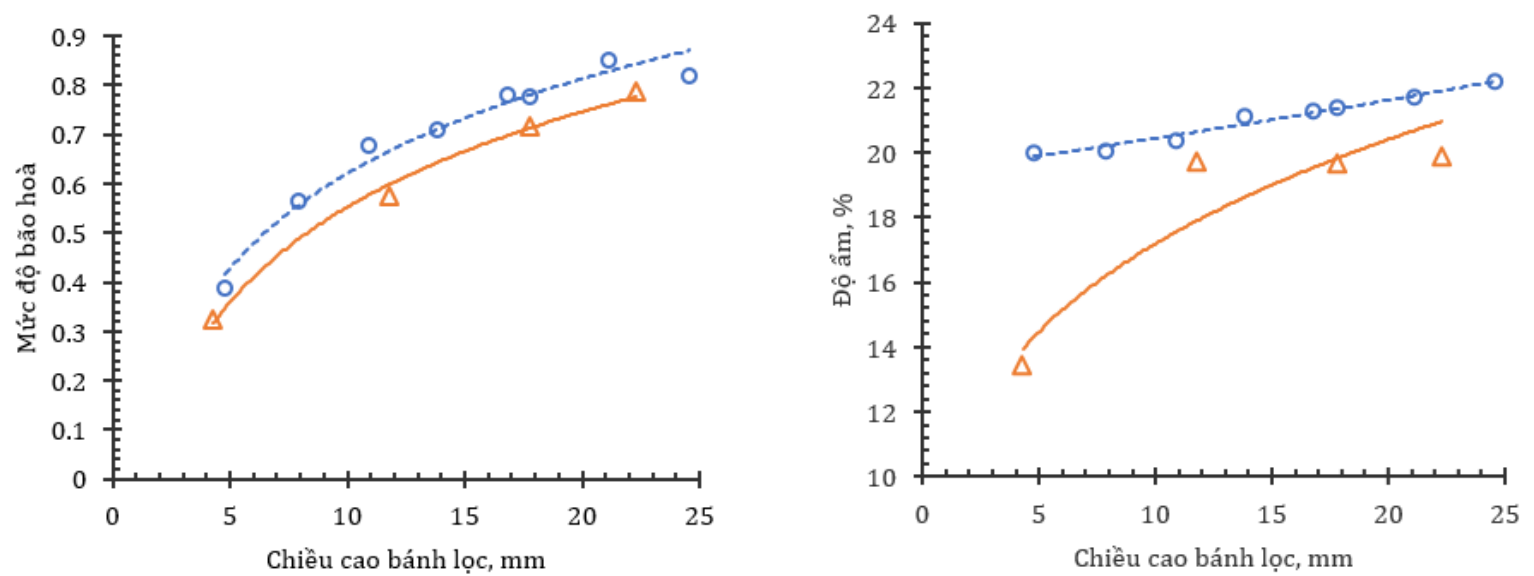

Hình 8. Mức độ bão hoà và độ ẩm của bánh lọc khi tăng chiều cao bánh lọc; áp suất 3 - 3 bar; hàm lương phần rắn 0,1 (cv). (ký hiệu hình tròn, nét đưt: lọc tăng áp truyền thống; ký hiệu tam giác, nét liền: lọc hoi nước tăng áp). 
Bảng 1. Kết quả thí nghiệm cho một sốl loại vật liệu sử dụng lọc hơ nước cao áp (kết hợp 3 pha của quá trình lọc).

\begin{tabular}{|c|c|c|c|c|c|}
\hline & \multicolumn{2}{|c|}{$\begin{array}{c}\mathrm{KS} 100 \\
\left(x_{50}<20,68 \mu \mathrm{m}\right)\end{array}$} & \multirow{2}{*}{\begin{tabular}{|c}
$\begin{array}{c}\mathrm{KS} 12 \\
\left(x_{50}<2,46 \mu \mathrm{m}\right)\end{array}$ \\
0,3 \\
\end{tabular}} & \multicolumn{2}{|c|}{$\begin{array}{c}\text { VN coal } \\
\left(x_{50}<11,78 \mu \mathrm{m}\right)\end{array}$} \\
\hline Hàm lượng thể tích chất rắn trong bùn & 0,3 & 0,4 & & 0,3 & 0,4 \\
\hline $\begin{array}{l}\text { Độ chênh áp suất (pha hình thành bánh } \\
\text { lọc - pha dịch chuyển cơ học - pha sấy) }\end{array}$ & 3 - 3 - 3 bar & $3-3-3$ bar & 3 - 3 - 3 bar & 3 - 3 - 3 bar & 3 - 3 - 3 bar \\
\hline Khối lượng chất rắn, gam & 50 & 50 & 50 & 30 & 30 \\
\hline $\begin{array}{l}\text { Thời gian dòng không khí đi qua bánh lọc } \\
\text { trong pha sấy, giây }\end{array}$ & & & 150 & & \\
\hline Độ ẩm vật liệu tính theo khối lượng, \% & 9,05 & 6,73 & 16,12 & 13,78 & 12,65 \\
\hline
\end{tabular}

nước mang lại trong pha thứ ba (pha sấy của quá trình lọc), hiệu quả khử nước còn cao hơn rất nhiều, (kết quả được thể hiện ở nghiên cứu sơ bộ trong phần tiếp theo).

Một nhận xét giá trị tiếp theo khi bình luận về kết quả thí nghiệm đó là xu hướng giảm hiệu quả khử nước khi bánh lọc trở nên dày hơn. Ở chiều cao $20 \mathrm{~mm}$, bánh lọc có mức độ bão hoà $0,74 \div 0,82$ (tương ứng là $18,8 \div 22 \%$ của độ ẩm). Giá trị này cao so với kỳ vọng ở cả lọc hơi nước và lọc truyền thống. Nguyên nhân có thể liệt kê là do hiệu ứng ngăn máy, sự phân bố không đồng đều mật độ các hạt tại các vị trí cụ thể khi hình thành bánh lọc, sự hình thành các kết hạt trong pha đầu tiên của quá trình lọc, sự phân tầng của các hạt chất rắn trong quá trình hình thành bánh lọc. Tuy nhiên, đây chỉ là các giả thuyết và cần có các nghiên cứu sâu hơn để giải thích cho hành vi này. Trong phạm vi bài báo, các vấn đề này không được đề cập sâu hơn.

\subsubsection{Kết quả thí nghiệm gồm 3 pha quá trình lọc}

Như đã trình bày ở trên, quá trình lọc bao gồm 3 pha: pha hình thành bánh lọc, pha dịch chuyển cơ học và pha sấy. Trong các thiết bị lọc truyền thống (chân không và cao áp), pha sấy có rất ít tác dụng, đặc biệt với vai trò giảm độ ẩm vật liệu do chỉ có dòng khí đi qua các lỗ rỗng trong bánh lọc ở nhiệt độ thường. Lượng nước bám dính trên bề mặt các hạt khoáng cũng như tồn tại trong kẽ nứt của các hạt khoáng vật không thể được loại bỏ hoàn toàn theo cách này. Ngoài ra, lượng nước còn tồn tại ở các lỗ rỗng nhỏ và siêu nhỏ trong hệ thống bánh lọc. Tuy nhiên, đối với quá trình lọc hơi nước cao áp, trong quá trình dịch chuyển qua hệ thống bánh lọc ở pha dịch chuyển cơ học, các hạt vật liệu được truyền nhiệt và trở nên nóng hơn đến nhiệt độ tương ứng với mức áp suất tại vị trí đó. Nước tồn tại trong bánh lọc tiếp tục được bốc hơi. Vai trò của dòng khí nén trong pha sấy giúp mang lượng hơi nước này ra ngoài, giảm đáng kể độ ẩm sản phẩm, thậm chí trong các trường hợp vật liệu trở nên khô hoàn toàn (Peuker \& Stahl, 2001). Kết quả thí nghiệm bao gồm cả pha sấy ở Bảng 1 cho thấy độ ẩm cuối của một số loại vật liệu. Với thời gian dòng không khí nén đi qua bánh lọc là 150 giây, áp suất khí nén 3 bar, độ ẩm của các loại vật liệu dưới 10\% với KS100, khoảng 16\% với KS12, và khoảng $13 \%$ đối với than bùn mịn của nhà máy Tuyển than Cửa Ông, Việt Nam. Các giá trị này đối với lọc thông thường là $20 \div 25 \%$. Kết quả cho thấy hiệu quả của lọc hơi nước tăng áp đối với khử nước vật liệu hạt mịn. Hiệu quả khử nước không chỉ ở pha thứ hai mà còn tiếp tục ở pha thứ ba của quá trình lọc nhờ hiệu ứng nhiệt.

Ưu điểm vượt trội của lọc hơi nước tăng áp là quá trình khử nước cơ học và quá trình nhiệt được kết hợp trong cùng một thiết bị. Điều này giúp giảm chi phí đầu tư, xây dựng cơ bản, và chi phí sản xuất (đặc biệt loại bỏ quá trình sấy nhiệt). Mô hình của lọc hơi nước có thể được chế tạo dựa trên các thiết bị lọc hiện nay như lọc băng tải, lọc tang trống, lọc đĩa, lọc ép khung bản.

Một ưu điểm nữa cần phải được đề cập đó là do cơ chế hình thành lớp nước ngưng tụ trong pha thứ hai, lọc hơi nước cao áp làm tăng hiểu quả rửa bánh lọc, loại bỏ tạp chất, các hóa chất độc hại trong bánh lọc. Ngày nay, lọc hơi nước đang được coi là lựa chọn tối ưu trong xử lý bùn đỏ của quá trình sản xuất alumin.

\section{Kết luận và kiến nghị}

\subsection{Kết luận}

Lọc hơi nước về bản chất là quá trình kết hợp khử nước cơ học và nhiệt trong cùng một thiết bị. Vật liệu được khử nước hiệu quả hơn đáng kể so 
với lọc truyền thống mà không cần sử dụng các quá trình đắt tiền sau đó như các thiết bị sấy nhiệt.

Hiệu quả khử nước ở pha thứ hai và thứ ba của quá trình lọc cao hơn so với lọc truyền thống do bản chất nguyên lý đặc biệt của lọc hơi nước. Các thông số quan trọng đầu vào là hàm lượng thể tích chất rắn của bùn quặng và chiều cao bánh lọc được nghiên cứu. Kết quả khử nước được thể hiện chủ yếu ở pha dịch chuyển cơ học, do đây là pha quan trọng nhất, ảnh hưởng đến hiệu quả khử nước. Ngoài ra pha sấy cũng giúp giảm sâu hơn nữa độ ẩm của vật liệu nhờ lượng nhiệt dư thừa tồn tại bên trong bánh lọc trong quá trình sử dụng hơi nước ở pha thứ hai. Kết quả pha sấy chỉ dừng lại ở một vài nghiên cứu sơ bộ để thấy rõ hiểu quả của lọc hơi nước.

\subsection{Kiến nghị}

Cần có những nghiên cứu sâu hơn về pha sấy của quá trình lọc hơi nước, tối ưu hoá thời gian của pha để đạt được độ ẩm thấp nhất và đảm bảo được năng suất.

Ngoài ra, nhằm mục đích sử dụng hiệu quả lọc hơi nước dựa trên những ưu thế đặc biệt của quá trình này, một số vấn đề cần được nghiên cứu sâu:

- Đánh giá hiệu quả rửa của quá trình lọc hơi nước, triển vọng ứng dụng loại bỏ hoá chất, chất độc hại tồn tại trong các sản phẩm do quá trình chế biến trước đó. Nghiên cứu ứng dụng trong xử lý bùn đỏ của ngành công nghiệp sản xuất alumin ở Việt Nam.

- Đánh giá khả năng ứng dụng các thiết bị lọc hơi nước trong các nhà máy tuyển khoáng, luyện kim, tái chế.

- Đánh giá khả năng sử dụng nước biển với vai trò nguồn cung cấp hơi nước chủ yếu.

- Mô phỏng quá trình lọc hơi nước cao áp.

\section{Lò̀i cảm on}

Tác giả xin chân thành cảm ơn đồng nghiệp ở Viện Kỹ thuật chế biến cơ học và Tuyển khoáng, Trường Đại học Kỹ thuật Bergakademie Freiberg đã giúp đỡ để hoàn thành nghiên cứu này. Cảm ơn sự giúp đỡ về học thuật và thảo luận của Thomas Buchwald, Simon Esser, Erik Löwer. Cảm ơn Silke Thümmler và Annett Kästner cho các phép đo nhiễu xạ laser, hiển vi điện tử quét, Thomas Hantusch cho các hỗ trợ chế tạo thiết bị thí nghiệm.
Tác giả cũng gửi lời cảm ơn đến sự hỗ trợ tài chính cũng như các thủ tục để nghiên cứu tại CHLB Đức từ đề án 911 của Bộ Giáo dục và Đào tạo Việt Nam, cơ quan trao đổi hàn lâm CHLB Đức (DAAD), tổ chức giáo dục quốc tế (WUS).

\section{Đóng góp của tác giả}

Phạm Thanh Hải - Khái niệm hoá, phương pháp luận, kiểm chứng, tiến hành thí nghiệm, viết bản thảo; Phạm Thanh Hải và Urs Peuker - Phân tích dữ liệu, đánh giá, chỉnh sửa.

\section{Tài liệu tham khảo}

Alkhatib, H., (2008). Comparison of Sequential Monte Carlo Filtering with Kalman Filtering for Nonlinear State Estimation. 1st Internatinal Conference on Machine Control Guidance.

Alkhatib, H. N., (2008). Comparison of Sequential Monte Carlo Filtering with Kalman Filtering for Non - linear State Estimation. 1st International Conference on Machine Control and Guidance.

Aussems, T., (1999). Positionsschätzung von Landfahrzeugen mittels Kalman - Filterung aus Satelliten - und Koppelnavigations beobachtungen. Veröffentlichung des Geodätischen Instituts der Rheinisch Westfälischen Technischen Hochschule.

Baganz, G., (1930). German Đăng ký độc quyền nhãn hiệu số 498,590.

Bott, R., \& Langeloh, T., (1996). Steam pressure filtration - Advanced version of the continuous pressure filtration (Hi - bar filtration). Aufbereitungstechnik/Mineral Processing, 163 - 179.

Bott, R., Langeloh, T., \& Meck, F., (2002). Continuous seam pressure filtration of mass mineral products. Aufbereitungstechnik/ Mineral Processing, 19 - 30.

Brown, J., (1964). The mechanism of dewatering by steam filtration. Annual General Meeting, (trang 105 - 109). Montreal.

Burton, G., (1962). A new process to reduce the mositure content in filter cakes. Fourth International Congress for Coal Processing. Harrowgate. 
Douc, R., Olivier, C., \& Eric, M., (2005). Comparison of resampling schemes for particle filtering. Image and Signal Processing and Analysis, Proceedings of the 4th International Symposium on.

Efron, B., (1979). Bootstrap methods : another look at the Jackknife. The annals of Statistics, 7(1), 1 - 26.

Esser, S., \& Peuker, U., (2020). (Data in Brief)). Temperature data during steam pressure filtration in combination with the water insoluble pore liquid. Chemical Engineering Science, 31.

Esser, S., \& Peuker, U., (2020). Steam pressure filtration in combination with a water insolube pore liquid. Chemical Engineering Science, 225.

Gerl, S., (1999). Steam Pressure Filtration, a mechanical - thermal differential pressure process for filter cakes (in German). VDI Verlag, Düsseldorf, 241.

Gerl, S., \& Stahl, W., (1995). Experimental studies on steam pressure filtration of coal concentrate filter cakes. XIX IMPC Congress. San Francisco.

Gerl, S., \& Stahl, W., (1997). Dewatering of coal and ore filter cakes by steam pressure filtration. $X X$ IMPC Congress. Aachen.

Gerl, S., \& Stahl, W., (2007). Improved Dewatering of Coal by Steam Pressure Filtration. Coal Preparation, 137 - 146.

Gordon, N. S., (1993). Novel approach to non linear/non - Gaussian Bayesian state estimation. IEE Proceedings, 140(2), 107 - 113.

Gösele, W., Alt, C., \& Loeve, T., (2005). Filtration, in Ullmann's Encyclopedia of Industrial Chemistry. Weinheim: Wiley_VCH verlag GmbH\&Co.

Gustafsson, F., (2002). Particle Filter Theory and Practice with Positioning Applications. IEEE Transactions on Signal Processing, 50(2), 425 437.

Jose', L. J., (2013). Simultaneous Localization and Mapping for Mobile Robots - introduction and method (lần xuất bản 1). USA: IGI Global.

Julier, J. U., (1997). A New Extension of the Kalman
Filter to Non - linear Systems. Seattle, Washington: In The Proceedings of the American Control Conference.

Julier, S. U., (2004). Unscented filtering and nonlinear estimation. Proceedings of the IEEE, 92(3), 401 - 422.

Kalman, R., (1960). A new approach to Linear Filtering and Prediction Problems. Transaction of the ASME - Journal of Basic Engineering, 33 45.

Liu, J. C., (1998). Sequential Monte Carlo Methods for Dynamic systems. Journal of the American Statistical Association, 93(443), 1032 - 1044.

Löwer, E., Pham, T., Leißner, T., \& Peuker, U., (2020). Study on the influence of solids volume fraction on filter cake structures using microtomography. Powder Technology, 286 299.

Peuker, U., (2018). Steam pressure filtration Technology for dry tailings stockage. International Mineral Processing Congress (trang 899 - 906). International Agency of Congress Management.

Peuker, U., \& Stahl, W., (2001a). Scale - up and operation of a steam pressure filter in pilot scale (in German). Chemie Ingenieur Technik.

Peuker, U., \& Stahl, W., (2001b). Steam pressure filtration: Mechanical - thermal dewatering process. Drying Technology, 807 - 848.

Peuker, U., Stahl, W., Bott, R., \& Langeloh, T., (2000). Scale - up and operation of a steam pressure filtration in pilot scale. ACHEMA. Frankfurt.

Peuker, U., Stahl, W., Bott, R., Langeloh, T., \& Blessing, G., (2001). Steam - pressure filtration: an improve procedure for the processing of FGD gypsum. VGB PowerTech, 88 - 92.

Pham, T. H., \& Peuker, U., (2020). Shrinkage cracking during filtration experiment Influence of suspension concentration on crack formation. ISRM 2020 (trang 385 - 406). Springer, Cham.

Pitt, M. S., (1999). Filtering Via Simulation: Auxiliary Particle Filters. Journal of the American Statistical Association (American 
Statistical Association), 94(446), 590 - 591.

Ramm, K., (2008). Evaluation von Filter Ansätzen für die Positionsschätzung von Fahrzeugen mit den Werkzeugen der Sensitivitätsanalyse. Reihe C, Nr. 619: DGK.

Redeker, D., Steiner, K. - H., \& Esser, U., (1983). Das mechanische Entfeuchten von Filterkuchen. Chemie Ingenieur Technik, 820 - 839.

Rushton, A., Ward, A., \& Holdich, R., (2015). Solid liquid Filtration and Separation Technology. Weinheim, Germany: VCH Verlag.

Särkkä, S., (2013). Bayesian filtering and smoothing (xuất bản lần 1). Cambridge University Press.

Schweitzer, J.. (2012). Modular Positioning using Different Motion Models. Stuttgart, Germany: In the Proceedings on 3rd International Conference on Machine Control and Guidance.

Schweizer, M., (2012). System - oriented efficiency optimization of variable speed drives. Diss., ETH Zürich.

Silverblatt, C., \& Dahlstrom, D., (1964). Improved dewatering of coal bt steam filtration: experimental bench scale tests. Trans. of Society of Mining Engineers. Salt Lake City.

Sparks, C., (2016). Filter and Filtration Handbook. USA: Joe Hayton.

Sternberg, H., (2000). Zur Bestimmung der Trajektorie von Lanfahrzeugen mit einem hybriden Meßsystem. Heft 67, Neubiberg:
Schriftenreihe des Studiengangs Vermessungwesen der Universität der Bundeswehr München.

Svarovsky, L., (2001). Introduction to solid - liquid separation, in Solid - liquid separation (Fourth Edition). Butterworth - Heinemann: Oxford. P. 1 - 29.

v.d. Gathen, R., (1963). Dewatering of coal slurry on a steam hood filter (in German). Glückauf, 1374 - 1380.

VDI - 2762. (2010). Mechanical solid - liquid separation by cake filtration. Part 2: Determination of filtercake resistance. Berlin: Beuth - Verlag.

Wakeman, R., (2007). The influence of particle properties on filtration. Separation Purification Technology, 234 - 241.

Wan, A. V., (2002). The Unscented Kalman Filter. Trong Kalman Filtering and Neural networks (trang 221 - 282). New York: Wiley.

Wan, A. V., (2002). The Unscented Kalman Filter, Kalman Filtering and Neural networks.

Welch, G. B., (1995). An introduction to the Kalman filter. Chapel Hill, USA: Technical report TR 95 - 041 University of North Carolina.

Wiedemann, T., \& Stahl, W., (1996). Experimental investigation of the shrinkage and cracking behaviour of fine particle filter cake. Chemical Engineering and Processing: Process Intensification, 35 - $42 .$. 